\title{
Early childhood obesity: a survey of knowledge and practices of physicians from the Middle East and North Africa
}

Inge Gies ${ }^{1}$, Bader AlSaleem², Beheshteh Olang ${ }^{3}$, Berkouk Karima ${ }^{4}$, Gamal Samy $^{5}$, Khaled Husain ${ }^{6}$, Mahmoud Elhalik , Mohamad Miqdady ${ }^{8}$, Mohamad Rawashdeh ${ }^{9}$, Mohamed Salah ${ }^{10}$, Nezha Mouane ${ }^{11}$, Pejman Rohani ${ }^{3}$, Atul Singhal ${ }^{12}$ and Yvan Vandenplas ${ }^{1 *}$

\begin{abstract}
Background: Childhood obesity is one of the most serious public health issues of the twenty-first century affecting even low- and middle-income countries. Overweight and obese children are more likely to stay obese into adulthood. Due to the paucity of data on local practices, our study aimed to assess the knowledge and practices of physicians from the Middle East and North Africa region with respect to early-onset obesity.

Methods: A specific questionnaire investigating the perception and knowledge on early-onset obesity was circulated to healthcare providers (general physicians, pediatricians, pediatric gastroenterologist, neonatologists) practicing in 17 Middle East and North African countries.

Results: A total of 999/1051 completed forms (95\% response) were evaluated. Of all respondents, 28.9\% did not consistently use growth charts to monitor growth during every visit and only $25.2 \%$ and $46.6 \%$ of respondents were aware of the correct cut-off criterion for overweight and obesity, respectively. Of those surveyed, 22.3, 14.0, $36.1,48.2$, and $49.1 \%$ of respondents did not consider hypertension, type 2 diabetes, coronary heart disease, fatty liver disease, and decreased life span, respectively, to be a long-term complication of early childhood obesity. Furthermore, only $0.7 \%$ of respondents correctly answered all survey questions pertaining to knowledge of early childhood overweight and obesity.

Conclusion: The survey highlights the low use of growth charts in the evaluation of early childhood growth in Middle East and North Africa region, and demonstrated poor knowledge of healthcare providers on the short- and long-term complications of early-onset obesity. This suggests a need for both continued professional education and development, and implementation of guidelines for the prevention and management of early childhood overweight and obesity.
\end{abstract}

Keywords: Early nutrition, Early childhood obesity, Middle East and North Africa region, Growth charts, Overweight, Professional education

\footnotetext{
* Correspondence: yvan.vandenplas@uzbrussel.be

'Department of Pediatrics, UZ Brussel, Vrije Universiteit Brussel, Brussels,

Belgium

Full list of author information is available at the end of the article
}

(c) The Author(s). 2017 Open Access This article is distributed under the terms of the Creative Commons Attribution 4.0 International License (http://creativecommons.org/licenses/by/4.0/, which permits unrestricted use, distribution, and reproduction in any medium, provided you give appropriate credit to the original author(s) and the source, provide a link to the Creative Commons license, and indicate if changes were made. The Creative Commons Public Domain Dedication waiver (http://creativecommons.org/publicdomain/zero/1.0/) applies to the data made available in this article, unless otherwise stated. 


\section{Background}

Childhood obesity is one of the most serious public health issues of the twenty-first century affecting even low- and middle-income countries [1]. As per WHO 2013 estimate, 42 million children under the age of 5 years are overweight or obese [1]. Overweight and obese children are more likely to stay obese into adulthood and to develop cardiovascular diseases at a younger age [1].

Epidemiologic data show that nutrition, pre- and postnatal, affects long-term health outcomes throughout life [2]. The first 1000 days of life (from conception to 2 years of age) are recognized as a critical time period when unmet nutritional needs may adversely impact short- and long-term health and physical and psycho-motor development [3]. The growth acceleration hypothesis proposes that faster post-natal growth (upward weight percentile crossing - particularly in infancy) may program several components of the metabolic syndrome, including insulin resistance, higher low-density lipoprotein cholesterol concentration, and higher blood pressure, resulting in obesity [4]. Initiation and longer duration of exclusive breastfeeding, lower protein intake during the first 2 or 3 years of life, and introduction of complementary feeding between the age of 4-6 months have all been associated with a lower risk of becoming overweight [5-11]. Nutritional approaches in the perinatal period may potentially contribute to the lifetime burden of non-communicable diseases [2] and, at present, is a major focus of nutritional research [12].

Although guidelines have been published on both the prevention and management of early childhood obesity, no studies have evaluated the knowledge and daily practice of healthcare providers. The main objective of this study was to assess the knowledge and practices of healthcare providers (general physicians, pediatricians, pediatric gastroenterologist, neonatologists) living in the Middle East and North Africa (MENA) region with respect to early-onset obesity.

\section{Methods}

A group of national and international pediatricians specializing in pediatric obesity developed a questionnaire to investigate the attitudes of MENA physicians towards the early onset of overweight and obesity in this region (see Additional file 1 for questionnaire).

There are no universally agreed upon definitions for overweight and obesity in early childhood [13]. For the study, overweight was defined as weight-for-length above the 85th percentile and obesity was defined as weightfor-length above the 95th percentile [13].

The questionnaire was divided into two main sections. The first section included seven questions on demographic details of participants such as age, gender, practice setting, country of origin, and specialism.
The second section included six questions assessing physicans' knowledge about early childhood overweight and obesity, including the importance of early childhood obesity for short- and long-term health, systematic use of growth charts during each child's visit, growth parameters (weight, length, head circumference, weight/height ratio, or a combination of previous parameters), cut-off criteria for infant overweight and obesity, and awareness of obesity comorbidities (cardiovascular disease, fatty liver disease, decreased life span, hypertension, type 2 diabetes).

Questionnaires were distributed between March and October 2015 to attendees of national and regional general pediatric meetings in participating countries from the MENA region. Descriptive statistics were used to summarize the demographics of the respondents and their responses to the questions.

\section{Results}

\section{Physician characteristics}

A total of 1051 questionnaires were retrieved between March and October 2015. Six questionnaires were excluded because they were incomplete and a further 46 were excluded because the physician's specialty was not reported. Analysis was performed on data from 999 completed survey forms (95\% response rate) (Table 1). Seventeen countries from the MENA region (Algeria, Egypt, Iran, Iraq, Jordan, KSA, Kuwait, Lebanon, Macedonia, Morocco, Oman, Palestine, Sudan, Syria, Tunis, UAE, and Yemen) participated in the survey. The largest proportion of respondents were from Morocco (21.2\%), Jordan (12.4\%), Iran (12.8\%), KSA (11.1\%), Egypt (8.4\%), Algeria (8.4\%), Lebanon (8.1\%), Kuwait (7.5\%), and UAE (7.3\%).

Of the participating physicians, $54.1 \%$ of respondents were male, $78.7 \%$ worked at government facilities, and 90.5\% were in full-time employment. Most respondents were pediatricians (71\%) followed by family doctors (22\%). The majority of respondents (74\%) were aged below 50 years ( $44 \%$ were below 40 years, $30 \%$ were $40-50$ years, $23 \%$ were $50-60$ years, and 3\% were over 60 years). Furthermore, only $0.7 \%$ of the surveyed physicians responded correctly to all the survey questions.

\section{Routine use of growth charts}

Growth charts were used by more than $70 \%$ of respondents aged below 40 years and between 50 and 60 years. Growth charts were not used by $28.9 \%$ of respondents at every visit, and this finding was highly prevalent in those over 60 years $(34.6 \%)$. Growth charts were more frequently used by physicians practicing in Algeria (94\%), UAE (91.7\%), Lebanon (89.9\%), and Morocco (86.3\%), than in Kuwait (45.9\%) and Iran (31.5\%). A higher percentage of surveyed male physicians $(32.6 \%)$ did not use growth charts compared with female physicians (24.7\%). 
Table 1 Characteristics of physicians surveyed

\begin{tabular}{|c|c|c|}
\hline Characteristics & Number (N) & Percentage (\%) \\
\hline Total & 999 & 100 \\
\hline \multicolumn{3}{|l|}{ Age } \\
\hline$<40$ years & 434 & 43.4 \\
\hline $40-50$ years & 293 & 29.3 \\
\hline $50-60$ years & 223 & 22.3 \\
\hline$>60$ years & 27 & 2.7 \\
\hline Not reported & 22 & 2.2 \\
\hline \multicolumn{3}{|l|}{ Gender } \\
\hline Male & 533 & 53.3 \\
\hline Female & 452 & 45.2 \\
\hline Not reported & 14 & 1.4 \\
\hline \multicolumn{3}{|l|}{ Specialty } \\
\hline General physicians & 222 & 22.2 \\
\hline Pediatrics & 707 & 70.8 \\
\hline Pediatric gastroenterologists & 58 & 5.8 \\
\hline $\begin{array}{l}\text { Other (Neonatologists and } \\
\text { NICU specialists) }\end{array}$ & 12 & 1.2 \\
\hline \multicolumn{3}{|l|}{ Practice facility } \\
\hline Government & 786 & 78.7 \\
\hline Private & 204 & 20.4 \\
\hline Other or not reported & 9 & 0.9 \\
\hline \multicolumn{3}{|l|}{ Country of practice } \\
\hline Algeria & 84 & 8.4 \\
\hline Egypt & 84 & 8.4 \\
\hline Iran & 128 & 12.8 \\
\hline Jordan & 124 & 12.4 \\
\hline KSA & 111 & 11.1 \\
\hline Kuwait & 75 & 7.5 \\
\hline Lebanon & 81 & 8.1 \\
\hline Morocco & 212 & 21.2 \\
\hline UAE & 73 & 7.3 \\
\hline $\begin{array}{l}\text { Others (Canada, Iraq, Macedonia, } \\
\text { Oman, Palestine, Sudan, Syria, } \\
\text { Tunis, Yemen) }\end{array}$ & 27 & 2.7 \\
\hline
\end{tabular}

Growth parameters such as weight, length, head circumference, and weight/length ratio were commonly assessed by physicians (Fig. 1). These findings were reflected equally across age groups. The majority of respondents across all age groups did not monitor weight/length ratio, with $64.5 \%$ of respondents aged below 40 years, $57.3 \%$ from 40 to 50 years, $53.4 \%$ from 50 to 60 years, and $51.9 \%$ above 60 years. Only 17\% of all respondents monitored all parameters.

Cut-off for overweight was defined as weight/length ratio $\geq 85$ percentile [13] by $25.2 \%$ and obesity was defined as weight/length ratio $\geq 95$ percentile [13] by
$46.6 \%$ of the respondents (Fig. 2). Almost 20\% of physicians did not know the cut-off for overweight and obesity during infancy. Table 2 shows that the definition of overweight and obesity was similar across physicians of all age groups.

Perception of early childhood obesity as a medical problem The majority of physicians, regardless of age group, practicing in the MENA region (83.1\%), thought childhood obesity was a serious issue. However, early childhood obesity was not considered a serious problem by $16.9 \%$ of respondents.

\section{Awareness of early childhood obesity-related comorbidities}

The awareness of obesity-related comorbidities such as hypertension, type 2 diabetes mellitus, coronary heart disease, decreased life span, and fatty liver disease were assessed (Fig. 3). A combination of all listed comorbidities was only known to $32.1 \%$ of physicians. Only half of all respondents (50.9\%) thought decreased life span was associated with early childhood obesity. Furthermore, most respondents (96.7\%) were not aware of other obesity-related comorbidities.

\section{Discussion}

The MENA region is known to harbor the highest prevalence of type 2 diabetes in adult populations worldwide, with underlying obesity as one of its main causes [14]. Data on early childhood obesity in the region are sparse, but clearly indicate a trend of increasing early-onset obesity [15] and increasing prevalence of metabolic syndrome in the childhood obesity population $[16,17]$. Changes in dietary pattern, particularly early introduction of sweetened beverages and premature introduction of cow's milk and complementary feeding, have been linked to earlyonset obesity in the MENA region [18].

Therefore, healthcare professionals (HCPs) play a crucial role in the prevention and early diagnosis of infant and childhood obesity. Overall, our study confirms that HCPs in the MENA region regard early childhood obesity as being a serious healthcare burden. However, 16.9\% of the physicians did not consider early childhood obesity as a serious condition.

Our study highlighted two key problems. Firstly, infant obesity appears to be underdiagnosed due to the lack of standardized use of growth charts during infant consultations. Importantly, one third of the questioned physicians did not use growth charts during routine consultations, and this was seen uniformly across age groups. One of the reasons for not plotting growth data could be the lack of time or the absence of knowledge on how to effectively use growth charts. This trend is not only demonstrated in our study, but 


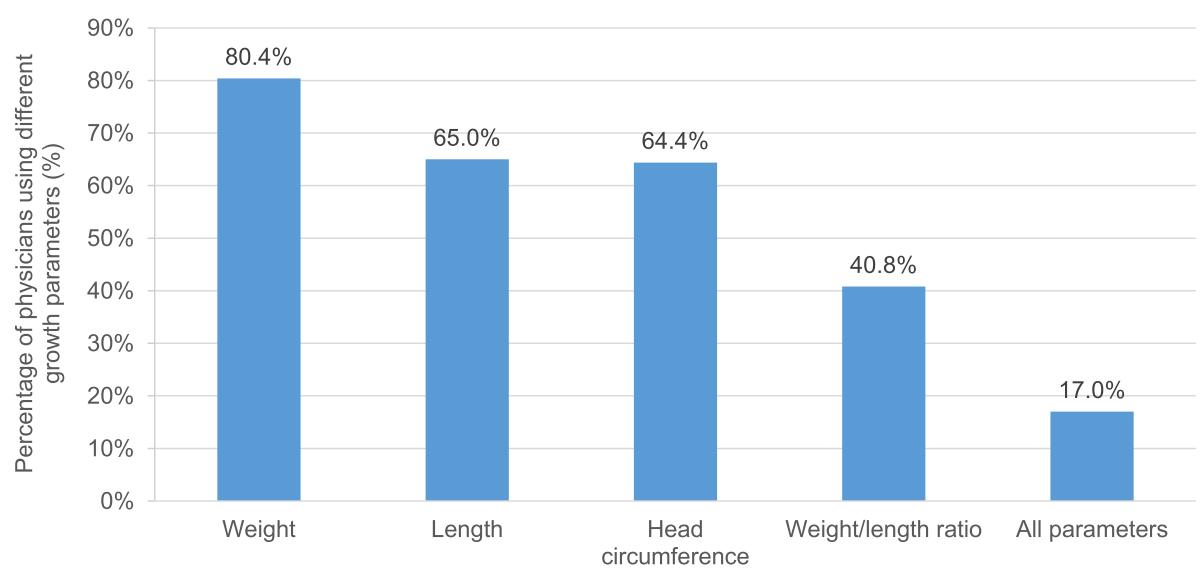

Fig. 1 Parameters used to evaluate growth

has been reported by other studies [19-23] conducted worldwide. Two Australian studies revealed that about two-thirds of general practitioners do not routinely measure children's height or weight $[19,20]$. A recent study comparing the attitudes, skills, and practices in childhood obesity management of physicians practicing in Poland, Ukraine, France, and Italy found that $80 \%$ of Italian, $48.7 \%$ of French, $32.5 \%$ of Polish, and $6.1 \%$ of Ukrainian doctors routinely plotted growth charts [21]. Data from Israel and the United States suggested that some HCPs did not use growth charts because of lack of knowledge on interpretation of data [22, 23]. This was confirmed by our survey results because a varied response to cut-off values for overweight and obesity was recorded. A reason for this may due to the lack of international uniformity in cut-off values for the diagnosis of childhood obesity, debating the use a global or local growth charts, and which age groups to monitor regularly. No consensus exists on the definition of infant obesity, underlying the urgent need for standardization and simplification of definitions in infant and childhood obesity.

Secondly, physicians from the MENA region appear to not be aware of the complications associated with early-onset obesity. In our study, 22.3, 14, 36.1, and $48.2 \%$ of HCPs did not correlate hypertension, type 2 diabetes, coronary heart disease, and fatty liver disease, respectively, to be a long-term complication of childhood obesity. Most strikingly, almost half of all respondents (49.1\%) did not associate decreased life span with childhood obesity. Data from Mazur et al. [21] stressed that most primary healthcare providers recognized the need for professional education in obesity management and the need for training in dietary counseling. Furthermore, Walker et al. [24] and Crawford et al. [25] reported that lack of training is a barrier to proper management of obesity, and that regular and repeated training of both HCPs and the general community is needed to raise and maintain
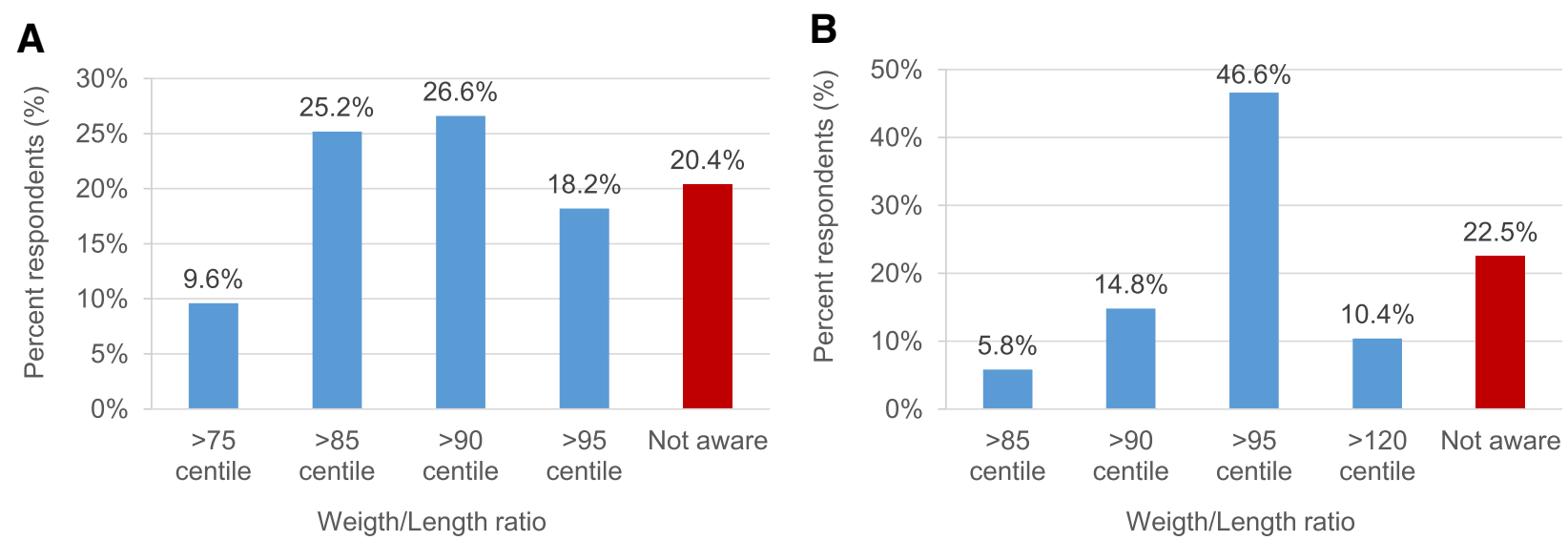

Fig. 2 Cut-off for defining overweight (a) and obesity (b) 
Table 2 Cut-off for defining overweight (A) and obesity (B) categorized by physician age

\begin{tabular}{|c|c|c|c|c|}
\hline Weight/Length (percentile) & $<40$ years & $40-50$ years & $50-60$ years & $>60$ years \\
\hline \multicolumn{5}{|l|}{ [A] Defining overweight } \\
\hline$n$ & 421 & 285 & 215 & 25 \\
\hline$>75$ & $11.2 \%$ & $9.8 \%$ & $7.4 \%$ & $8.0 \%$ \\
\hline$>85$ & $22.1 \%$ & $28.8 \%$ & $24.2 \%$ & $36.0 \%$ \\
\hline$>90$ & $28.7 \%$ & $22.5 \%$ & $27.9 \%$ & $28.0 \%$ \\
\hline$>95$ & $16.9 \%$ & $17.5 \%$ & $21.4 \%$ & $8.0 \%$ \\
\hline Not aware & $21.1 \%$ & $21.4 \%$ & $19.1 \%$ & $20.0 \%$ \\
\hline \multicolumn{5}{|l|}{ [B] Defining obesity } \\
\hline$n$ & 418 & 282 & 214 & 22 \\
\hline$>85$ & $7.2 \%$ & $4.3 \%$ & $5.1 \%$ & $9.1 \%$ \\
\hline$>90$ & $16.0 \%$ & $14.5 \%$ & $12.1 \%$ & $13.6 \%$ \\
\hline$>95$ & $43.8 \%$ & $51.1 \%$ & $45.3 \%$ & $45.5 \%$ \\
\hline$>120$ & $9.1 \%$ & $8.9 \%$ & $15.4 \%$ & $9.1 \%$ \\
\hline Not aware & $23.9 \%$ & $21.3 \%$ & $22.0 \%$ & $22.7 \%$ \\
\hline
\end{tabular}

the awareness of the complications of childhood obesity. Furthermore, only $0.7 \%$ of physicians responded correctly to all the survey questions, warranting the need for repeated professional education, to leverage expertise and improve overall health outcomes within the MENA region.

The main limitation of our study is that the information was primarily based on feedback from respondents practicing in nine out of the 17 participating MENA countries, which may not be representative of the overall situation. Furthermore, because physicians who completed the questionnaire were self-selecting (i.e. causing a bias due to individuals selecting themselves into a group), we cannot be sure that respondents were representative of the physicians in their country or region. This is particularly important because of the large and diverse physician population in this region. We used descriptive statistics to analyze survey data as only $0.7 \%$ of physicians responded correctly to all the survey questions. We have not used inferential statistical models, as they would not provide additional information to the already evident need for repeated professional education in the MENA region.

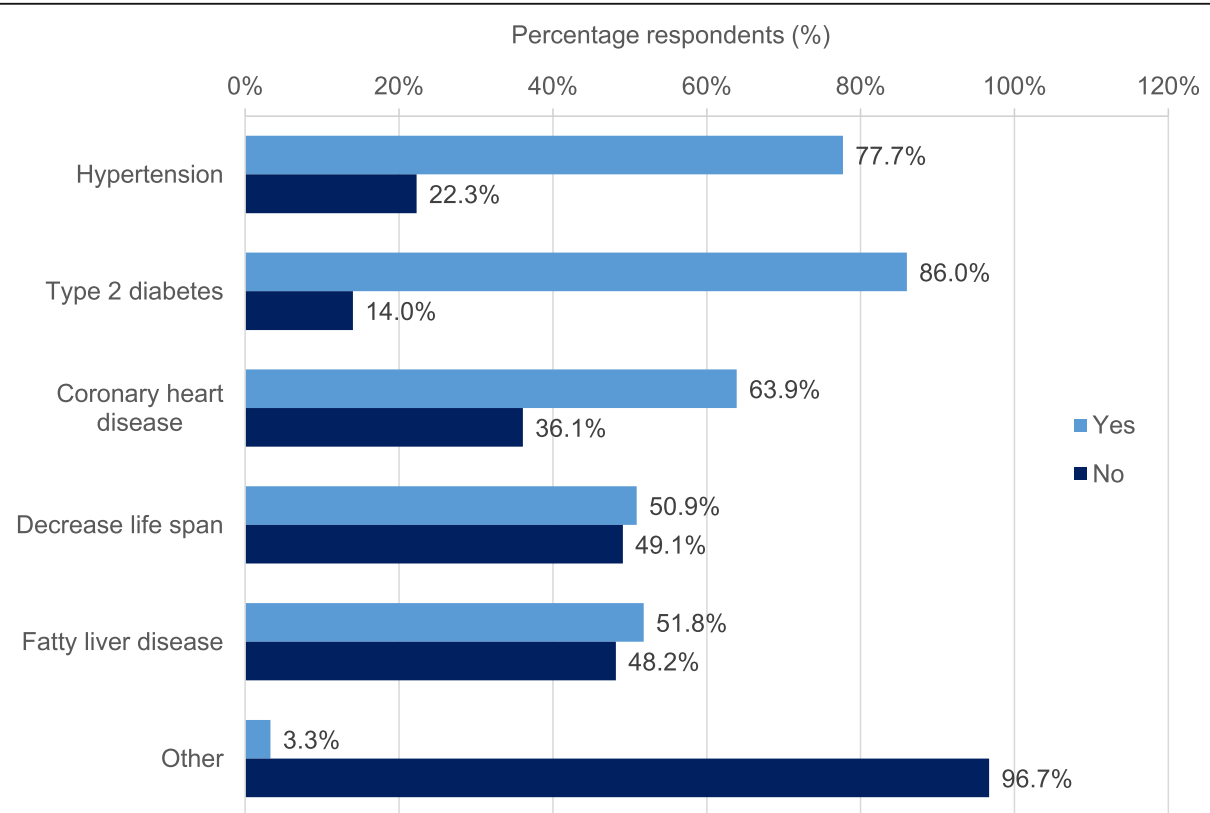

Fig. 3 Prevalence of awareness of early childhood obesity-related comorbidities 


\section{Conclusions}

This study was the first to report practices and knowledge on use and interpretation of growth charts and on the knowledge of early childhood obesity of HCPs working in the MENA region. Since this region in prone to a high incidence of (childhood) obesity, our data could improve strategies for proper recognition and diagnosis of early-onset obesity, and further stress the need for repeated education of physicians on childhood obesity. Data from this study may be used to develop best practice recommendations that can be easily adapted to a local setting with the final aim of decreasing the incidence of early-onset obesity and reducing the long-term burden on the healthcare system.

Use of growth charts in the evaluation of childhood growth is low in the MENA region, which is similar to Western countries. Knowledge on the short- and longterm complications of early-onset obesity is limited in this region, and the development and implementation of clear guidelines on the prevention and management of childhood obesity are warranted.

\section{Additional file}

Additional file 1: Description of data: English version of the questionnaire used in the study. (DOCX $30 \mathrm{~kb}$ )

\section{Abbreviations}

BF: Breastfeeding; BMI: Body Mass Index; CF: Complimentary Feeding; HCP: Health Care Professional; HM: Human Milk; MENA: Middle East and North Africa; WHO: World Health Organization

\section{Acknowledgments}

Medical writing support was provided by Marcus Corander and Leris D'Costa of OPEN Health Dubai, UAE. Statistical analysis was performed by Leonard Kauffman of DICE.

\section{Funding}

Nestlé Nutrition Institute Middle East provided support and honoraria for all the authors who attended the meeting for questionnaire development, they also funded the medical writing and data analysis support. The authors were collectively responsible for the study design as well as the analysis and interpretation of data and the writing of the manuscript.

\section{Availability of data and materials}

The datasets during and/or analyzed during the current study available from the corresponding author on reasonable request.

\section{Authors' contribution}

IG and $Y$ conceived and led the design of the study, analyses, and drafting of the article. IG wrote the first draft of the paper. IG, BA, BO, BK, GS, KH, ME, $M M, M R, M S, N M, P R, A S$, and $Y$ contributed to the development of the survey, discussion of the data analysis and critical review of the manuscript. All authors read and approved the final manuscript.

\section{Competing interests}

The authors declare that they have no competing interests.

\section{Consent for publication}

Not applicable.

\section{Ethics approval and consent to participate}

Ethics and IRB approval was granted from the Institute of Postgraduate Childhood Studies, Ain Shams University, Cairo, Egypt. Written informed consent waiver was received prior to study initiation. Completion of the questionnaire constituted assumed consent to participate from the responding physicians.

\section{Publisher's Note}

Springer Nature remains neutral with regard to jurisdictional claims in published maps and institutional affiliations.

\section{Author details}

'Department of Pediatrics, UZ Brussel, Vrije Universiteit Brussel, Brussels, Belgium. ${ }^{2}$ Pediatric Gastroenterology, Hepatology and Nutrition Department, Children's Hospital, King Fahad Medical City, King Saud bin Abdulaziz University for Health Sciences, Riyadh, Kingdom of Saudi Arabia. ${ }^{3}$ Mofid Children's Hospital, Shahid Beheshti University of Medical Sciences, Tehran, Iran. ${ }^{4}$ Hepatology and Nutrition Society Group Member, Maillot Hospital Algiers, Algeria, Gastroenterology, Algiers, Algeria. ${ }^{5}$ Department of Medical Childhood Studies, Institute of Postgraduate Childhood Studies, Ain Shams University, Cairo, Egypt. ${ }^{6}$ Pediatric Gastroenterology, Hepatology and Nutrition Unit, Department of Pediatrics, Amiri Hospital, Arabian Gulf Street, Kuwait City, Kuwait. ${ }^{7}$ Pediatric and Neonatology Department, Latifa Hospital, Dubai Health Authority, Dubai, United Arab Emirates. ${ }^{8}$ Pediatric

Gastroenterology, Hepatology and Nutrition Division, Sheikh Khalifa Medical City, Abu Dhabi, United Arab Emirates. ${ }^{9}$ Department of Pediatrics, Jordan University Hospital, Amman, Jordan. ${ }^{10}$ Nestlé Nutrition, Dubai, United Arab Emirates. ${ }^{11}$ Gastroenterology Nutrition Department, Children Hospital Ibn Sina, University Mohammed V Faculty of Medicine, Rabat, Morocco. ${ }^{12}$ The Childhood Nutrition Research Centre, Institute of Child Health, University College London, London, UK.

Received: 12 August 2016 Accepted: 14 April 2017

Published online: 28 April 2017

\section{References}

1. WHO. Childhood overweight and obesity on the rise. http://www.who.int/ dietphysicalactivity/childhood/en/. Accessed 2 Aug 2015.

2. Koletzko B, Symonds ME, Olsen SF, Project ENP. Academy EN programming research: where are we and where do we go from here? Am J Clin Nutr. 2011;94(6 Suppl):2036S-43S.

3. Christian P, Mullany LC, Hurley KM, Katz J, Black RE Nutrition and maternal, neonatal, and child health. Semin Perinatol. 2015:39:361-72.

4. Singhal A, Lanigan J. Breastfeeding, early growth and later obesity. Obes Rev. 2007:8(Suppl 1):51-4.

5. Harder T, Bergmann R, Kallischnigg G. Plagemann a duration of breastfeeding and risk of overweight: a meta-analysis. Am J Epidemiol. 2005; 162(5):397-403.

6. Hediger ML, Overpeck MD, Kuczmarski RJ. Ruan WJ association between infant breastfeeding and overweight in young children. JAMA. 2001;285(19): 2453-60.

7. Michaelsen KF, Greer FR. Protein needs early in life and long-term health. Am J Clin Nutr. 2014;99(3):718S-22S.

8. Weber M, Grote V, Closa-Monasterolo R, Escribano J, Langhendries JP, Dain E, Giovannini M, Verduci E, Gruszfeld D, Socha P, et al. Lower protein content in infant formula reduces $\mathrm{BMI}$ and obesity risk at school age: follow-up of a randomized trial. Am J Clin Nutr. 2014;99(5):1041-51.

9. Young BE. Krebs NF complementary feeding: critical considerations to optimize growth, nutrition, and feeding behavior. Curr Pediatr Rep. 2013; 1(4):247-56.

10. Jonsdottir $\mathrm{OH}$, Thorsdottir I, Hibberd PL, Fewtrell MS, Wells JC, Palsson Gl, Lucas A, Gunnlaugsson G. Kleinman RE timing of the introduction of complementary foods in infancy: a randomized controlled trial. Pediatrics. 2012;130(6):1038-45

11. Vandenplas Y, De Ronne N, Van De Sompel A, Huysentruyt K, Robert M, Rigo J, Scheers I, Brasseur D. Goyens P a Belgian consensus-statement on growing-up milks for children 12-36 months old. Eur J Pediatr. 2014;173(10): 1365-71.

12. Lanigan J. Singhal a early nutrition and long-term health: a practical approach. Proc Nutr Soc. 2009;68(4):422-9. 
13. Ogden CL, Carroll MD, Kit BK. Flegal KM prevalence of obesity and trends in body mass index among US children and adolescents, 1999-2010. JAMA. 2012;307(5):483-90.

14. Sherif S. Sumpio BE economic development and diabetes prevalence in MENA countries: Egypt and Saudi Arabia comparison. World J Diabetes. 2015;6(2):304-11.

15. Kelishadi R, Haghdoost AA, Sadeghirad B. Khajehkazemi R trend in the prevalence of obesity and overweight among Iranian children and adolescents: a systematic review and meta-analysis. Nutrition. 2014;30(4) 393-400.

16. Zaki ME, Mohamed SK, Bahgat KA. Kholoussi SM metabolic syndrome components in obese Egyptian children. Ann Saudi Med. 2012;32(6):603-10.

17. Aboul Ella NA, Shehab DI, Ismail MA. Maksoud AA prevalence of metabolic syndrome and insulin resistance among Egyptian adolescents 10 to 18 years of age. J Clin Lipidol. 2010;4(3):185-95.

18. Nasreddine L, Zeidan MN, Naja F. Hwalla N complementary feeding in the MENA region: practices and challenges. Nutr Metab Cardiovasc Dis. 2012; 22(10):793-8.

19. Spurrier NJ, Magarey A. Wong C recognition and management of childhood overweight and obesity by clinicians. J Paediatr Child Health. 2006;42(7-8):411-8.

20. King LA, Loss JH, Wilkenfeld RL, Pagnini DL, Booth ML, Booth SL. Australian GPs' perceptions about child and adolescent overweight and obesity: the weight of opinion study. Br J Gen Pract. 2007;57(535):124-9.

21. Mazur A, Matusik P, Revert K, Nyankovskyy S, Socha P, Binkowska-Bury M, Grzegorczyk J, Caroli M, Hassink S, Telega G, et al. Childhood obesity: knowledge, attitudes, and practices of European pediatric care providers. Pediatrics. 2013;132(1):e100-8.

22. Kolagotla L. Adams W ambulatory management of childhood obesity. Obes Res. 2004;12(2):275-83.

23. Goldman RD, Modan-Moses D, Bujanover Y, Glasser S. Meyerovitch J Physicians' attitude toward identification and management of childhood obesity in Israel. Clin Pediatr. 2004;43(8):737-41.

24. Walker O, Strong M, Atchinson R, Saunders J. Abbott J a qualitative study of primary care clinicians' views of treating childhood obesity. BMC Fam Pract. 2007;:5:50.

25. Crawford PB, Gosliner W, Strode P, Samuels SE, Burnett C, Craypo L. Yancey AK walking the talk: fit WIC wellness programs improve self-efficacy in pediatric obesity prevention counseling. Am J Public Health. 2004;94(9):1480-5.

\section{Submit your next manuscript to BioMed Central and we will help you at every step:}

- We accept pre-submission inquiries

- Our selector tool helps you to find the most relevant journal

- We provide round the clock customer support

- Convenient online submission

- Thorough peer review

- Inclusion in PubMed and all major indexing services

- Maximum visibility for your research

Submit your manuscript at www.biomedcentral.com/submit 